University Physics

By Dr. F. C. Champion. Part 3 : Light. Pp. viit 172. 5s. 6d. net. Part 4: Wave-Motion and Sound. Pp. vii +67. 5s. net. (London, Glasgow and Bombay: Blackie and Son, Ltd., 1941.)

THESE two books form part of a complete course in physics for university students. Both books are clearly and soundly written, and are excellently produced. There is a group of examples after each chapter, and at the end of edch book there is a number of questions with answers and useful hints for solution.

"Light". In a book avowedly written for university students, and occupying only 172 pages, it is rather surprising to find space taken up with elementary work. Certain sections are marked with an asterisk indicating that Intermediate students may omit them, but not everybody will agree with Dr. Champion's selection of the parts to be omitted. The chapter on photometry is very good, though probably more information might have been given on photo-electric instruments, while the chapter on the emission and wave theories of light is excellent and makes one wish for more.

"Sound". In this book, which runs to only 57 pages of text, Dr. Champion starts with a treatment of wave motion and simple harmonic waves. This is an excellent beginning, but as one goes through the book one finds that in many cases just the basic information is given. This is probably the author's intention; nevertheless the students for whom the book has been written will require more.

Undoubtedly what Dr. Champion has given is excellent, but he has not given enough; a bibliography of reference books would probably have been helpful to students.

\section{Mathematics for Engineers}

By Raymond W. Dull. Second edition. Pp. xviii 780. (New York and London: McGraw-Hill Book Co., Inc., 1941.) 35s.

7 HIS is the second edition of the author's treatise on mathematics designed for engineers. It was originally published in 1926 and the major change in this new issue lies in the addition of several new operations with the slide rule-which the writer calls the "engineer's assistant"-made possible by modern improvements in the design of that useful instrument. The course is intended to bridge the gap between the engineer's handbook and the purely mathematical text-book, the former being too concise and incomplete, while the latter is too specialized. Considerable space is assigned to the treatment of error-absolute and relative-and to practical use of the slide rule.

The artificial boundaries between the various branches of the subject are commendably swept aside and, between the simple arithmetic of the first chapter and the multiple integration of the last, there is, in the intervening fifty-five chapters, a comprehensive and practical review of algebra, pure and analytical geometry, mensuration, trigonometry, including complex numbers, and calculus. The text is well illustrated by worked examples and clearly drawn diagrams. A few minor misprints are notice. able in which the phrase, "knots per hour", may be be included. As a review and work of reference, the book should be quite useful to those for whom it was written.
The Foundations of Geometry

By Prof. Gilbert de B. Robinson. (Mathematical Expositions, No. 1.) Pp. $x i+167$. (Toronto: University of Toronto Press, 1940.) 2 dollars.

7 HERE are several excellent treatises dealing exhaustively with modern ideas of geometry and analysis, but the bulk and difficulty of these works repel those who are not specialists. The University of Toronto is publishing a series of "Mathematical Expositions", which will present topics in a readable fashion, with particular attention to showing how modern theories of mathematics arise naturally from considerations well known to elementary students. The first volume, Prof. Robinson's "The Foundations of Geometry", carries out this programme so far as it concerns the more usual kinds of geometry, leaving non-Euclidean geometry to be dealt with in a later volume. Part I considers the axiomatic foundation of projective geometry and of Euclidean geometry, and shows the relation between these. Part II deals with the more difficult questions of number, order and continuity. Those with a good knowledge of school geometry should find the book very helpful as a bridge between the old domains and the new.

Future volumes in this series will include "The Infinite in Mathematics" and "The Theory of Interest".

\section{Opera hactenus inedita Rogeri Baconi}

Fasc. 16: Communia Mathematica Fratris Rogeri. Partes prima et seconda. Nune primum edidit Dr. Robert Steele. Pp. xii +162 . (Oxford : Clarendon Press; London: Oxford University Press, 1940.) 15s. net.

D OGER BACON (1214-1294) produced in 1267 his four-volume Latin encyclopædic treatise ("Opus Majus") on the foundations of knowledge, with two supplements dealing with physical science and mathematics. The "Communia Mathematica" appears to be an amplified version of the second supplement, assembled from various manuscripts by someone unknown, probably about 1428. For the modern reader the interest of the work is mainly in showing what mathematical literature and teaching were available at the time, and what Bacon thought of the teaching of Boethius, who moulded scientific thought of the early Middle Ages until the complete acceptance of Aristotle's physics. The first part of the "Communia" deals with the relation of mathematics to other branches of learning. The second part considers certain parts of mathematics in detail, particularly the theory of proportion. The criticism of some of Euclid's assumptions and definitions shows that Bacon was far in advance of this time. As is well known, he was accused of magic and condemned to imprisonment for life.

\section{Differential Equations}

By G. S. Diwan and Prof. D. S. Agashe. Pp. $x+316$. (Bombay : Prof. D. S. Agashe, St. Xavier's College, 1941.) n.p.

7 HIS book, intended for a first degree course in Indian universities, gives a rather detailed account of the usual devices for obtaining a compact solution of differential equations designed to yield to the appropriate device. For this purpose it may be found useful.
L. M. M.-T. 